\title{
Influence of psycho-sexual factors on the quality of life in pregnant women during the COVID-19 pandemic: A Path Analysis
}

Masoumeh Alijanpour

Tarbiat Modares University Faculty of Medical Sciences

Shahideh Jahanian Sadatmahalleh ( $\nabla$ shahideh.jahanian@modares.ac.ir)

Tarbiat Modares University Faculty of Medical Sciences https://orcid.org/0000-0002-7006-8487

Youseflu Samaneh

Zanjan University of Medical Sciences

Bahri Khomami Mahnaz

Monash University Department of Epidemiology and Preventive Medicine

Yousefi Afrashteh Majid

Zanjan University of Medical Sciences

Ashraf Moini

University of Tehran

Anoshiravan Kazemnejad

Tarbiat Modares University Faculty of Medical Sciences

\section{Research article}

Keywords: Covid-19 pandemic, pregnant women, QoL, FSFI, General health

Posted Date: January 8th, 2021

DOI: https://doi.org/10.21203/rs.3.rs-45196/v3

License: (c) (1) This work is licensed under a Creative Commons Attribution 4.0 International License. Read Full License 


\section{Abstract}

Introduction: COVID-19 has spread rapidly around the world. This epidemic has created stress and anxiety for pregnant women in different parts of the world.

Objective: The aim of this study was to investigate the relationship between quality of life (QoL) with anxiety, depression, coronavirus induced anxiety, sexual function (SF), and marital satisfaction (MS) in pregnant women during the Covid-19 pandemic.

Methods: The present study is a cross-sectional study involving 261 pregnant women, administered through an online survey.

Outcomes: The Short-Form Health Survey (SF_12), Marital Satisfaction Scale (MSS), Female Sexual Function Index (FSFI), Hospital Anxiety and Depression Scale (HADS), and coronavirus induced anxiety questionnaire, Padua Obsession Questionnaire, General Health Questionnaire (GHQ) are used for data collection. Data were analyzed using the Pearson correlation coefficient and path analysis.

Results: The overall goodness-of-fit statistics revealed that the predictors of QoL had excellent fitness indices (RMSEA=0.02; AGFI=0.99). The results show that coronavirus induced anxiety, marital satisfaction (MS), sexual function (SF), depression, and anxiety have a direct effect on women's QoL. Among the variables, GHQ has a more direct effect on women's QoL. General health $(\mathrm{GH})$ is considered as a mediator variable; variables such as anxiety, depression, and coronavirus induced anxiety with effect on $\mathrm{GH}$ can impress QoL. Anxiety as a main predictor of QoL, with direct and indirect effects through GH, depression, SF, and MS can impress QoL.

Conclusion: Since the QoL in pregnant women is associated with coronavirus epidemics, these results can be used to plan to improve the health and QoL of these people.

\section{Introduction:}

In late 2019, a new virus, named sars cov-2 was identified as the effect of a group of pneumonia in Wuhan, China. COVID-19 is spreading rapidly, after the spread of the disease throughout China, then more cases occurred in other countries around the world $(1,2)$.

Because COVID-19 has spread rapidly worldwide, it caused fear and anxiety among the general population, especially among certain groups such as pregnant women (3). Nowadays, the effects of stress on the immune system are well known, as a result, humans are prone to all kinds of mental and physical illnesses (4). One of the determinants of mental health is the quality of life (QoL). It is important to assess the QoL to determine physical, mental, and social functioning (5).

QoL is a broad concept that is influenced by a complex form of physical health, psychological state, level of independence, and social communication, and the relationship between these factors and prominent environmental characteristics of individuals (6). One of the important physical and psychological 
dimensions of women's QoL is the quality of people's sexual life, which is influenced by many factors in a person's life and plays a decisive role in women's life and health (7).

Measuring QoL is essential in planning for mothers and infants' care, and it is also important for policymakers and health care providers to have this care (8). Meanwhile, pregnant women are vulnerable groups that need to develop evidence-based recommendations to protect the health of mothers and children (9). The coronavirus epidemic has created stress and anxiety for pregnant women in different parts of the world. Concern and stress in pregnancy are associated with adverse pregnancy outcomes such as preeclampsia, depression, increased nausea and vomiting during pregnancy, preterm labor, low birth weight, and low apgar score $(10,11)$.

It is unclear whether the suppression of the immune system during pregnancy affects the course of the disease. Available data suggest that pregnancy and childbirth do not increase the risk of developing COVID19 infection (9). On the other hand, it appears that pregnant women infected with the virus, especially those with pneumonia, have an increased rate of preterm labor, premature amniotic sac rupture, preeclampsia, and cesarean delivery due to abnormal fetal heart rate that probably was related to the mother's serious illness (12).

Since pregnant mothers are vulnerable, pregnancy is a physiological condition that exposes women to viral infections. Given the pandemic of coronavirus and the effects that it may have on different parts of people's lives, especially in pregnant women (2), there are concerns relating to the potential effect on maternal and neonatal outcome; therefore, pregnant women constitute a group that requires special attention.

This study aimed to test a conceptual model considering the interrelated role of anxiety, depression, marital satisfaction (MS), general health (GH), obsession, sexual function (SF), and coronavirus induced anxiety on the QoL of pregnant women. According to the above aims, this study proposes the following hypotheses (Hypotheses 1-4):

Hypothesis 1: A higher level of coronavirus induced anxiety will be associated with a lower level of QoL, MS, $\mathrm{GH}$, and higher levels of anxiety, depression, and contamination obsessions.

Hypothesis 2: A higher level of anxiety and depression will be associated with a lower level of MS, SF, GH, and QoL.

Hypothesis 3: A higher level of contamination obsession will be associated with a higher level of anxiety and depression and also have a worse effect on SF, MS, GH, and QoL.

Hypothesis 4: SF, GH, anxiety, and depression will be associated with MS and QoL

\section{Methods:}

\section{Design and Data Collection:}


The present cross-sectional study was performed on 261 pregnant women by a convenient sampling method. At first, 300 women complete the questionnaires, 39 women were excluded from study due to lack of entry criteria or not completing the questionnaires. An electronic questionnaire was used for collecting the data in order to observe the physical distance and prevent the virus. At first, the questionnaire link was designed, and the designed link was sent to all social groups that were only pregnant women. A questionnaire about study objectives and entry criteria and how to respond was mentioned on the first page. The present study is approved by the Research Ethics Committee of Tarbiat Modares University with code (IR.MODARES.REC.1399.022).

Participants in the study were 18-45-year-old pregnant women who were not in the high-risk group. High-risk groups include corticosteroid therapy (more than $12.5 \mathrm{mg} / \mathrm{dL}$ per week), a history of chemotherapy, malignancies, organ transplants, HIV patients, cardiovascular disease, high blood pressure, diabetes, and respiratory illness. Also, BMl above 40 before pregnancy, suffering from a mental disorder (in the demographic section, the history of mental disorder was asked), suffering from a sexual disorder, and using any drugs affecting the sexual response cycle were excluded from the study.

\section{Measures:}

Demographic characteristics are including age of woman, age at marriage, body mass index, province and city of residence, income amount, educational level, duration of the marriage, occupational status, and midwifery characteristics such as menstrual status, gestational age to week, gravid, para, abortion, intrauterine fetal death, history of infertility, number of children, type of previous delivery, and unplanned pregnancy (yes or no).

\section{Mental Health}

The General Health Questionnaire (GHQ) was developed in 1978 by Goldberg. The GHQ examines four dimensions: physical symptoms (1-7), anxiety and insomnia (8-14), social function (15-21), and depression (28-22) (13). The validity and reliability of this questionnaire have been confirmed in Iran (14).

\section{Depression and Anxiety}

Hospital Anxiety and Depression Scale (HADS) is used to diagnose and classify the severity of depression and anxiety. The tool consists of 14 questions consisting of two subscales of anxiety (HADS-A) and depression (HADS-D). Each question is ranked on a 4-point Likert scale. A total score of less than 8 indicates a normal range. A score of 8-10 indicates slight changes, and scores above 11 indicate high levels of anxiety and depression. The validity and reliability of this questionnaire were confirmed by Montazeri et al. (15).

\section{Coronavirus Disease Anxiety}

Coronavirus induced anxiety scale (CDAS) has been prepared and validated by Alipour et al. to measure anxiety caused by the outbreak of coronavirus in Iran. This tool has 18 items and 2 factors. Items 1 to 9 measure the psychological symptoms, and items 10 to 18 measure the physical symptoms. The tool is rated on a 4-point Likert scale; the highest and lowest scores given by the respondents in this questionnaire 
are 0 to 54 . High scores on this questionnaire indicate a higher level of anxiety in individuals. The reliability of this tool was obtained using Cronbach's alpha method for the first factor of 0.879 . The second factor was 0.861 and for the total questionnaire was 0.919 (16).

\section{Sexual Function}

The Female Sexual Function Index (FSFI) was designed by Rosen et al. In 2000. This tool includes 19 questions with six factors of sexual desire (2 questions), sexual arousal (4 questions), humidity (4 questions), orgasm (3 questions), satisfaction (3 questions), and pain (3 questions). The scores of each question have a response range from 0 to 5 , for which the score of 0 is considered when they don't have sexual activity, and the score of 5 is equivalent to better performance in that area (except for the first and second questions from 1-5 scores is given) if the sex is not established during the last month.. The minimum score for the total number of questions is 2 and the maximum score is 36 (17). The Persian version of this tool has been localizing, and the cut-off point for the Persian version of the tool 28 has been reported (18).

\section{Marital Satisfaction}

Marital Satisfaction Scale-shortened version (MSS) consists of 10 questions that measure marital satisfaction. Their scoring is in the form of a Likert scale of 1 to 5 . Questions $1,3,5,8,8$ are negative, and the scores are reversed. The total score of this questionnaire varies from 10 to 50 . High scores indicate a higher marital satisfaction. This questionnaire was conducted by Arab Ali Dosti et al. (19).

\section{Quality of life}

The Short Life Quality Form (SF-12) questionnaire consists of 12 items that examine eight factors: physical performance, physical role, social role, emotional role, body pain, general health, vitality, and mental health. The total score varies from 0 to 100 , and a higher score indicates the best conditions. The questions are in the form of a Likert with a score of 1 to 6 . The questionnaire's negative (reverse) questions include questions $1,8,9,10$, so their scoring is reversed. In Iran, the psychometric of this questionnaire was confirmed (20).

\section{Obsession}

The Padua Obsession Questionnaire was used to assess and measure obsessive-compulsive disorder. This survey has 39 questions composed of five subscales that examined (1) obsessional thoughts about harm to oneself or others; (2) obsessional impulses to harm self/others; (3) contamination obsessions and washing compulsions (10 questions); (4) checking compulsions (10 questions); and (5) dressing/grooming compulsions (3 questions). We used only contamination obsessions and washing compulsions subscale. Each item was rated on a 5-point Likert-type scale ranging from 0 to $4(0=$ never, $1=$ to some degree, $2=$ often, $3=$ extremely, $4=$ very extremely) with a score range of $0-40$. Higher scores represent greater pollution obsession status. The validity and reliability of this questionnaire were approved among the Iranian population (21).

\section{Data analysis:}


SPSS software version 22 and LISREL (8.8) were used to analyze the data. Multiple correlation coefficients were used to evaluate the relationship between QoL variables, marital satisfaction, sexual performance, anxiety and depression, mental health, and coronavirus induced anxiety. Normality assumption was checked via Kolmogorov-Smirnov test, and examined the correlation of the data using Pearson correlation coefficient.

Multiple regression only examines the effects of a set of independent variables that are assumed to affect the dependent variable. According to the previous subject and valid references, the final conceptual model was tested by the path method. Path analysis has been used to fit the specified pattern of causal relationships between variables. In this study, a conceptual model of path analysis to determine the simultaneous relationship of QoL variables, MS, SF, obsession, anxiety and depression, mental health, and coronavirus induced anxiety was fitted. After conducting the Goodness of Fit test and correcting the best fit, the acceptable model was determined. Path analysis determines how much each independent variable has an effect on the dependent variable, directly or indirectly.

For evaluation of the model fitness, Root means a square error of approximation (RMSEA), Adjusted Goodness of Fit Index (AGFI), Confirmatory Factor Analytic (CFI), and Chi-square/df were used. RMSEA values less than 0.07 , Chi-square/df lower than 3 , AGFI more than 0.9 , and CFI more than 0.95 are indicative of a good fitting model. T-value more than +2 or less than -2 were considered statistically significant.

\section{Results:}

Before analyzing the data, the necessary assumptions were evaluated (Figure $1 \& 2$ ). Questionnaires of three participants were excluded from the analysis due to missing values. Univariate and multivariate outlier data were evaluated with standard Z-score and Mahalanobis distance. There was no univariate outlier data due to the fact that none of the participants had a score greater than or less than three standard deviations from the mean. The Mahalanobis distance values also showed no multivariate outliers. The normality of the data was assessed with a skew value. For all variables, the skewness index was between 1 and -1 , confirming the normality of their distribution. Finally, the data from 261 participants were analyzed.

Out of 261 womentook part in this study, 121 individuals (46.4\%) aged between 20-30 years. The mean parity and duration of marriage of women were $0.81 \pm 0.06$ and $6.6 \pm 4.35$ years, respectively. The majority of participants (39.8\%) were in home quarantine for 2-3 days per week. In terms of educational level, $80.8 \%$ of participants had a university education, and 51.7 percent had a monthly income between 1 and 3 million Toman. The overall mean score of QoL was 71.98 \pm 6.60 (Table1).

Table 2 shows the correlation (bivariate analysis) between all variables included to the path model. Results showed that QoL was correlated with $S F(r=0.36, P<0.001)$, anxiety $(r=-0.52, P<0.001)$, depression $(r=-0.46$, $P<0.001), \operatorname{CDAS}(r=-0.30, P<0.001)$, contamination obsession $(r=-0.18, P<0.001), G H(r=-0.38, P<0.001)$, and MS $(r=-0.31, P<0.001)$.

Based on the conceptual model, the predictors of quality of life $(\mathrm{Q} O \mathrm{~L})$ had perfectly good fitness indices (Pvalue=0.36; $\chi 2=17.35 ; \mathrm{DF}=16 ; \chi 2$ /DF=1.08; RMSEA=0.02; $\mathrm{CFI}=0.99 ; \mathrm{AGFI}=0.99)$ (Table 3). We found that sexual function (SF) $(\beta=0.16)$, anxiety $(\beta=-0.53)$, depression $(\beta=-0.17)$, corona induced anxiety $(\beta=-0.27)$, 
general health $(\mathrm{GH})(\beta=-0.47)$, and marital satisfaction $(\beta=0.20)$ are main predictors of women's QoL. Among variables, $\mathrm{GH}$ has a more direct effect on women's QoL. Moreover, $\mathrm{GH}$ was considered as a mediator variable; variables such as anxiety $(\beta=13)$, depression $(\beta=0.19)$, and corona induced anxiety $(\beta=0.95)$ with effect on GH can impress QoL. Anxiety as a main predictor of QoL, with direct, and indirect effect through GH $(\beta=0.13)$, depression $(\beta=0.69)$, SF $(\beta=-0.33)$, and MS $(\beta=-0.25)$ can impress $Q o L$.

Corona induced anxiety with both direct and indirect effects changes QoL. Women with a higher level of corona induced anxiety score have a lower level of GH ( $\beta=0.95)$, SF $(\beta=-0.19)$, MS $(\beta=-0.14)$; and a higher level of anxiety $(\beta=0.57)$, depression $(\beta=0.40)$, and contamination obsession $(\beta=0.58)$.

\section{Discussion:}

Coronavirus (COVID-19) has challenged the health care system around the world. One of the main concerns about the disease is coronavirus's impact on pregnancy and its risk for pregnant women and their children (22). The pregnancy period alone is stressful and full of worries, and recently, the anxiety and worry were added by coronavirus's epidemic (10). What seems important these days is the formation of relationships and the emergence of behaviors that indicate society's critical nature, which can affect all aspects of people's lives. To the best of our knowledge, no research has been found to examine the relationship between these variables in pregnant women during the epidemic.

In the present study, path analysis showed that during the coronavirus epidemic, the QoL of pregnant women was associated with SF, anxiety, depression, coronavirus disease anxiety, GH, and MS.

Ferreira et al., 2012, concluded a significant relationship between sexual performance and QoL in pregnant women (23). Also, in the study of Nik Azin et al., 2013, a direct relationship was found between QoL and sexual performance. In this way, people with high sexual function had a higher QoL, both of which correspond to the present study results (24).

Sex and marital relationship are changed due to the multiple physical and psychological changes during pregnancy (7); stress and anxiety caused by bad news, fear of infecting oneself and one's family with coronavirus, changes in lifestyle, and normal relationships. Concerns about the future are stressors that can reduce libido and impair sexual function (25). On the other hand, many people tend to have sex because of emotional motivation and insecurity. Numerous studies have shown that more sex leads to less stress (26). Since one of the important physical and psychological dimensions of women's QoL is the quality of people's sexual life, it can be concluded that people with the proper SF will have a better QoL.

Another result of the study was the inverse relationship between QoL and depression and anxiety, which is in line with some studies $(27,28)$ Hence, as depression increases, QoL decreases.

Anxiety and depression during the pregnancy are serious health problems (29). Due to the sudden outbreak of coronavirus, people do not have access to enough information about the disease. Anticipated concerns among pregnant women such as fear of infection and transmission from mother to fetus, are common. As a result, the coronavirus can be expected to increase the risk of depression in pregnant women (30). 
Depression also causes adverse consequences of pregnancy and reduces the QoL by influencing the social and environmental psychology of QoL $(28,29)$.

The results of this study also showed that $\mathrm{GH}$ was more directly related to the QoL, and for the rest of the variables, they acted as intermediaries by relating to the impact $\mathrm{GH}$ on QoL. There is a negative and significant relationship between the QoL and mental health in pregnant women. In fact, due to the negative and I nverse correlation, it can be concluded that as QoL increases, the mental health of pregnant women decreases. Given that the high scores in the GHQ indicate a more mental disorder, the negative relationship between the two the variable shows that by increasing QoL scores, the scores of GHQ (mental disorder) decreased and this indicates that mental health is higher in women with a higher QoL.

The results of Nik Azin et al.'s 2013 study showed that there is a direct relationship between QoL, SF, and GH (24), and Fathi et al., 2013, also stated that there is a negative and significant relationship between GH and QoL in pregnant women (31), which are consistent with the results of the present study.

It should be noted that pregnancy is associated with significant changes in women's mental and physical health, and since social performance in pregnant women is lower than other members of society, it can have adverse effects on physical health, well-being, and QoL. $(31,32)$.

Many people, especially those at risk such as pregnant mothers, are forced to stay at home to prevent the coronavirus transmission. Long-term isolation or home-confinement may negatively affect psychosocial and mental health, especially causing stress, negative emotions, and impairing cognition . If prolonged, they may suppress the immune system and physiological functions. However, about $60 \%$ of pregnant women eliminate their physical activity during pregnancy, and it can be said that pregnancy causes women to stop their physical activity at this stage of life or reduce it. Besides, physical activity is directly related to the QoL and its dimensions. Hence, the QoL decreases with a decrease in physical activity (such as quarantine conditions). So, the study of Slimani et al. (2020) showed that physical activity was correlated with all QoL domains during a period of government-directed confinement and a limitation of personal freedom. It can be concluded that with government restrictions on home-confinement to reduce the incidence, can be expected that the physical activity of pregnant women will decrease compared to before the coronavirus epidemic, and therefore the QoL of pregnant women will decrease (32-36)

The present study results showed that anxiety, directly and indirectly, affects GH, depression, SF, MS, and QoL. to put it simply, pregnant women with a higher level of anxiety had a lower level of QoL.

Pregnancy is a special time, full of excitement and expectations, but for pregnant mothers, the coronavirus outbreak has caused fear, anxiety, and insecurity. Anxiety is a common symptom in patients with chronic respiratory distress that significantly reduces patients' QoL (33). Stress and anxiety can increase the risk of side effects during pregnancy, such as preterm birth, low birth weight, nausea and vomiting, low birth weight, and depression $(10,29)$.

In the present study, the results showed that coronavirus induced anxiety has both direct and indirect effects on QoL. Thus, pregnant women with higher levels of anxiety had better $\mathrm{GH}$, lower SF, and higher levels of 
anxiety, depression, and obsession.

The results of Alipour et al., 2020, showed a correlation between coronavirus induced anxiety and GH. Thus, increasing the score on the physical and psychological symptoms of coronavirus induced anxiety was significantly associated with physical symptoms, depression anxiety, and social dysfunction, which is consistent with the results of the present study (16). Also, the results of studies conducted by Durankuş et al. 2020, and Wu et al. 2020, showed that the coronavirus disease epidemic affected the anxiety and depression of pregnant women, so that the level of anxiety and depression in pregnant women was higher during the epidemic $(29,30)$.

Pregnancy is a stressful time for pregnant women. The prevalence of coronavirus induced anxiety has increased stress and anxiety worldwide (29). Coronavirus anxiety is common, and as individuals are unfamiliar with it and generate cognitive ambiguity about the virus, it tends to increase more. Fear of the unknowns reduces the perception of immunity in humans and has always been a concern for humans (34).

Anxiety has always been endorsed by committed professionals as a health-threatening variable (37). Different types of anxiety disorders can have different effects on SF (38). The findings of a 2013 study by Nick Azin et al. showed that sexual desire and satisfaction were associated with aspects of QoL and mental health (anxiety, stress, and depression) in pregnant women (24). Anxiety has a limit, and if itexceeds, it can certainly have devastating effects, including exacerbating obsessive-compulsive behaviors. Obsessive behavior has increased during the coronavirus outbreak. Obsessive-compulsive disorder leads to decreased social, family functioning, and QoL (39). The results of a 1988 study by Karno et al. showed that people with the obsessive-compulsive disorder tend to rate themselves on a lower level of QoL (40).

Facing a crisis prevents a person from working and performing well on the components of problem-solving communication, emotional roles and reactions, emotional involvement (conflict), and behavioral control, which will lead to a decrease in public health and, consequently, the QoL in the individual (41).

\section{Conclusion:}

The result of our study illustrated that SF, depression, anxiety, coronavirus induced anxiety, GH, and MS were the main predictors of the QoL of pregnant women during this crisis. According to the research findings, health managers can improve the QoL of these people by planning and holding virtual training to improve depression, anxiety, the mental health of pregnant women in this critical period.

\section{Abbreviations}

FSFI: Female Sexual Function Index

QoL: Quality of Life

SF12: Short Form Health Survey

SARS: Severe Acute Respiratory Syndrome 
MERS: Middle East Respiratory Syndrome

COVID19: Coronavirus Disease 2019

SF: Sexual Function

MS: Marital Satisfaction

WHO: World Health Organization

BIS: Behavioral Immune System

BMI: Body Mass Index

HADS: Hospital Anxiety and Depression Scale

GHQ: General Health Questionnaire

MSS: Marital Satisfaction Scale-Shortened version

RMSEA: Root Mean Square Error of Approximation

AGFI: Adjusted Goodness of Fit Index

CFI: Confirmatory Factor Analytic

DF: Degree of Freedom

\section{Declarations}

\section{Ethics approval and consent to participate}

The study was approved by the Ethics Committee of Tarbiat Modares University of Medical Sciences (IR.MODARES.REC.1399.022). All procedures were in accordance with the ethical standards of the Regional research committee and with the Declaration of Helsinki 1964 and its later amendments.

\section{Consent for publication}

Not applicable.

\section{Availability of data and materials}

The data sets used and analyzed during the current study are available from the corresponding author on reasonable request

\section{Competing interests}

The authors declare no conflict of interest. 


\section{Funding}

None.

\section{Authors' contributions}

Sh.JS, M.A, and S.Y contributed to the conception and design of the study; Sh.JS and M.A did the literature search; A.K, S.Y, M.YA, and M.B performed the statistical analysis; M.A, Sh.JS, S.Y, M.YA, and M.B wrote the first draft of the manuscript. All authors contributed to manuscript revision, read, and approved the submitted version.

\section{Acknowledgments}

This study was carried out with the kind collaboration of the participants. This study is a part of research work done in Tarbiat Modares University, Tehran, Iran. There were no conflicts of interest.

\section{References}

1. Ranganathan $R$, Khan AM, Chhabra P. Antenatal care, care at birth, and breastfeeding during the coronavirus (COVID-19) pandemic. Indian Journal of Community Health. 2020;32(1).

2. Yang $\mathrm{H}$, Wang $\mathrm{C}$, Poon L. Novel coronavirus infection and pregnancy. Ultrasound in Obstetrics \& Gynecology. 2020;55(4):435.

3. T N. What is mentalhealth? 2020/03/13; https://www.medicalnewstoday.com/articles/154543. .

4. Sadeghi-Yarandi M, Khodabakhshi-Koolaee A, Falsafinejad MR, Khaletbari N. The Interrelationship between Job Stress with the Immune System and Functional Memory of Women Working in Diagnostic Laboratories. The Neuroscience Journal of Shefaye Khatam. 2019;7(2):23-32.

5. Allart P, Soubeyran P, Cousson-Gélie F. Are psychosocial factors associated with quality of life in patients with haematological cancer? A critical review of the literature. Psycho-Oncology. 2013;22(2):241-9.

6. I. S. Investigating the relationship between early health and quality of life with the mediating role of spiritual health in students. Culture at the University of Islam. 2016;6(4):565-82.

7. Ajh, Samiei Rad F, Kalhor M, Hassanpour K, Alipour M, A M. Assessing the quality of sexual life of pregnant women: A cross-sectional study. Payesh. 2018;17(4):421-9.

8. Zeighami Mohammadi S, Ghaffari F. Sexual dysfunction and its correlation with quality of life among women affected with cancer. The Iranian Journal of Obstetrics, Gynecology and Infertility. 2009;12(2):39-46.

9. Coronavirus disease 2019 (COVID-19): Pregnancy issues [Internet]. 2019.

10. Fakari FR, Simbar M. Coronavirus Pandemic and Worries during Pregnancy; a Letter to Editor. Archives of Academic Emergency Medicine. 2020;8(1).

11. Pregnant And Worried About Coronavirus? How To Stay Safe And Make A Game Plan. [Internet]. March $22,2020$. 
12. Di Mascio D, Khalil A, Saccone G, Rizzo G, Buca D, Liberati M, et al. Outcome of Coronavirus spectrum infections (SARS, MERS, COVID 1-19) during pregnancy: a systematic review and meta-analysis. American journal of obstetrics \& gynecology MFM. 2020:100107.

13. Sterling M. General health questionnaire-28 (GHQ-28). Journal of physiotherapy. 2011;57(4):259.

14. Taghavi S. Validity and reliability of the general health questionnaire (GHQ-28) in college students of Shiraz University. Journal of psychology. 2002;5(4):381-98.

15. Montazeri A, Vahdaninia M, Ebrahimi M, Jarvandi S. The Hospital Anxiety and Depression Scale (HADS): translation and validation study of the Iranian version. Health and quality of life outcomes. 2003;1(1):14.

16. Alipour A, Ghadami A, Alipour Z, H. AZ. Preliminary validation of Corona Anxiety Scale (CDAS) in the Iranian sample. . Journal of Health Psychology. 2020;8(14):163-75.

17. Rosen CB, J. Heiman, S. Leiblum, C. Meston, R. Shabsigh, D. Ferguson, R. D'Agostino, R. The Female Sexual Function Index (FSFI): a multidimensional self-report instrument for the assessment of female sexual function. Journal of sex \& marital therapy. 2000;26(2):191-208.

18. Fakhri A, Pakpour AH, Burri A, Morshedi H, Zeidi IM. The Female Sexual Function Index: translation and validation of an Iranian version. The journal of sexual medicine. 2012;9(2):514-23.

19. ARAB AA, NAKHAEE N, KHANJANI N. Reliability and validity of the Persian versions of the ENRICH marital satisfaction (brief version) and Kansas Marital Satisfaction Scales. 2015.

20. Montazeri A, Vahdaninia M, Mousavi SJ, Omidvari S. The Iranian version of 12-item Short Form Health Survey (SF-12): factor structure, internal consistency and construct validity. BMC public health. 2009;9(1):341.

21. Shams G, Kaviani H, Esmaili Y, Ebrahimkhani N, Manesh AA. Psychometric properties of the persian version of the padua inventory: Washington State University Revision (PI-WSUR). Iranian journal of psychiatry. 2011;6(1):12.

22. Li R, Yin T, Fang F, Li Q, Chen J, Wang Y, et al. Potential risks of SARS-Cov-2 infection on reproductive health. Reproductive BioMedicine Online. 2020.

23. Ferreira DQ, Nakamura MU, Souza Ed, Mariani Neto C, Ribeiro MC, Santana TdGM, et al. Sexual function and quality of life of low-risk pregnant women. Revista Brasileira de Ginecologia e Obstetrícia. 2012;34(9):409-13.

24. Nik-Azin A, Nainian MR, Zamani M, Bavojdan MR, Bavojdan MR, Motlagh MJ. Evaluation of sexual function, quality of life, and mental and physical health in pregnant women. Journal of family \& reproductive health. 2013;7(4):171.

25. The effect of coronavirus on men [Internet]. 24/05/2020.

26. Here's what coronavirus anxiety might be doing to your sex drive. ABC Life. [Internet]. 2020.

27. Couto ER, Couto E, Vian B, Gregório Z, Nomura ML, Zaccaria R, et al. Quality of life, depression and anxiety among pregnant women with previous adverse pregnancy outcomes. Sao Paulo Medical Journal. 2009;127(4):185-9. 
28. Zoche E, Bosa VL, Chaves EBM, Capp E, von Eye Corleta H. Effect of depressive symptoms and HIV exposure on the quality of life of HIV-seropositive and seronegative pregnant women. Clinical \& Biomedical Research. 2019;39(2).

29. Durankuş F, Aksu E. Effects of the COVID-19 pandemic on anxiety and depressive symptoms in pregnant women: a preliminary study. The Journal of Maternal-Fetal \& Neonatal Medicine. 2020:1-7.

30. Wu Y-T, Zhang C, Liu H, Duan C-C, Li C, Fan J-X, et al. Perinatal Depression of Women Along with 2019 Novel Coronavirus Breakout in China. 2020.

31. Fathi A, Golakeh Khibari S. THE RELATIONSHIP BETWEEN PRENATAL CONCERNS, DEPRESSION, QUALITY OF LIFE AND GENERAL HEALTH OF PREGNANT WOMEN. Nursing And Midwifery Journal. 2018;15(12):939-49.

32. Basharpoor S, Soleymani E, Kazemi N, Nabi Salehi M. THE EFFECTIVENESS OF MINDFULNESS-BASED STRESS REDUCTION TRAINING ON IMPROVING THE QUALITY OF LIFE AND WELL-BEING OF PREGNANT WOMEN. The J Urmia Nurs Midwifery Fac. 2018;16(6):445-54.

33. Ayora AF, Soler LM, Gasch AC. Analysis of two questionnaires on quality of life of Chronic Obstructive Pulmonary Disease patients. Revista Latino-Americana de Enfermagem. 2019;27.

34. Bajema KL, Oster AM, McGovern OL, Lindstrom S, Stenger MR, Anderson TC, et al. Persons evaluated for 2019 novel coronavirus-United States, January 2020. Morbidity and Mortality Weekly Report. 2020;69(6):166.

35. Abbasi S, Moazami M, Bijeh N, Mirmajidi SR. Investigation of the relationship between physical activity levels, maternal weight (before delivery) and serum cortisol level (during labor) in nulliparous women. The Iranian Journal of Obstetrics, Gynecology and Infertility. 2015;18(151):12-9.

36. Slimani M, Paravlic AH, Mbarek F, Bragazzi NL, Tod D. The relationship between physical activity and quality of life during the confinement induced by COVID-19 outbreak: a pilot study in Tunisia. Frontiers in Psychology. 2020.

37. Dong X-Y, Wang L, Tao Y-X, Suo X-I, Li Y-C, Liu F, et al. Psychometric properties of the Anxiety Inventory for Respiratory Disease in patients with COPD in China. International journal of chronic obstructive pulmonary disease. 2017;12:49.

38. Hajnasiri $\mathrm{H}$, Aslanbeygi N, Moafi F, Mafi M. Investigating the relationship between sexual function and mental health in pregnant females. Iranian Journal of Psychiatric Nursing. 2018;6(2):33-40.

39. Ghaffari M, A. R. Investigating the relationship between marital satisfaction and quality of life with tendency to obsession and skill The life of married students of Payame Noor University. Journal of Medical Sciences, Islamic Azad University. 2013;23(2):140-7.

40. Karno M, Golding JM, Sorenson SB, Burnam MA. The epidemiology of obsessive-compulsive disorder in five US communities. Archives of general psychiatry. 1988;45(12):1094-9.

41. Nazoktabar H, Afrouzi FN. The Effect of Family Function on the Quality of Life and Mental Health of Pregnant Women referred to Health Centers of Babol City in the Year 2016. 2018.

\section{Tables}


Table 1: Socio-demographic Characteristics of Participants $(\mathrm{N}=261)$.

\begin{tabular}{ll}
\hline Variables & Number (Percent) \\
\hline Age (years) & $7(2.7)$ \\
Less than 20 years & $121(46.4)$ \\
Between 20-30 years & $99(37.9)$ \\
Between 30-35 years & $34(13)$ \\
More than 35 years & \\
\hline Duration of quarantine & \\
Less than 1 day/week & $25(9.6)$ \\
Between 2-3 day/week & $104(39.8)$ \\
Between 4-5 day/week & $73(28)$ \\
Between 6-7 day/week & $58(22.2)$ \\
At all & $1(0.4)$ \\
\hline Income (Toman) & $23(8.8)$ \\
Less than 1 million & $135(51.7)$ \\
Between 1-3 million & $85(32.6)$ \\
Between 3-5 million & $18(6.9)$ \\
More than 5 million & \\
\hline Education & $50(19.2)$ \\
$\leq 12$ years & $211(80.8)$ \\
\hline 12 years & Mean \pm SD \\
\hline Variables & $71.98 \pm 6.60$ \\
\hline QoL & $0.81 \pm 0.06$ \\
\hline Parity & $6.60 \pm 4.35$ \\
\hline Duration of marriage (years) & \\
\hline
\end{tabular}

Table 2. Correlations between Sexual function, Anxiety, Depression, Coronavirus induced anxiety, General health, Contamination obsession, Marital satisfaction, and Quality of life. 


\begin{tabular}{|c|c|c|c|c|c|c|c|}
\hline & $\begin{array}{l}\text { Sexual } \\
\text { function }\end{array}$ & Anxiety & Depression & CDAS & $\begin{array}{c}\text { General } \\
\text { health }\end{array}$ & $\begin{array}{c}\text { Contamination } \\
\text { obsession }\end{array}$ & $\begin{array}{l}\text { Quality } \\
\text { of life }\end{array}$ \\
\hline $\begin{array}{l}\text { Sexual } \\
\text { function }\end{array}$ & - & - & - & - & - & - & - \\
\hline Anxiety & $-0.37 * * *$ & - & - & - & - & - & - \\
\hline Depression & $0.48^{* * *}$ & $0.69 * * *$ & - & - & - & - & - \\
\hline CDAS & $-0.29 * * *$ & $0.57 * * *$ & $0.46^{* * *}$ & - & - & - & - \\
\hline $\begin{array}{l}\text { General } \\
\text { health }\end{array}$ & $-0.36^{* * *}$ & $0.64 * * *$ & $0.58^{* * *}$ & $0.95^{* * *}$ & - & - & - \\
\hline $\begin{array}{l}\text { Contamination } \\
\text { obsession }\end{array}$ & $-0.22^{* * *}$ & $0.37^{* * *}$ & $0.31 * * *$ & $0.58^{* * *}$ & $0.58 * * *$ & - & - \\
\hline Quality of life & $0.36^{* * *}$ & $-0.52 * * *$ & $-0.46^{* * *}$ & $-0.30 * * *$ & $-0.38 * * *$ & $-0.18^{* *}$ & - \\
\hline $\begin{array}{l}\text { Marital } \\
\text { satisfaction }\end{array}$ & $0.13 *$ & $-0.25^{* * *}$ & $-0.18 * *$ & $-0.20 * * *$ & $-0.19 * *$ & $-0.20 * * *$ & $-0.31 * * *$ \\
\hline
\end{tabular}

CDAS; Coronavirus induced anxiety scale

Values are given as Pearson coefficient (P-value) using Pearson correlation test.

$* \mathrm{P}<0.05 ; * * \mathrm{P}<0.01 ; * * * \mathrm{P}<0.001$.

Table 3. The goodness of Fit Indices for the Models.

\begin{tabular}{lcccccccc}
\hline & CFI & AGFI & RMSEA & $\chi^{2}$ & df & $\chi 2 / d f$ & P-value \\
\hline Path & 0.99 & 0.99 & 0.02 & 17.35 & 16 & 1.08 & 0.36 \\
$N=261$ & & & & & & & \\
\end{tabular}

CFI: Comparative Fit Index, AGFI: Adjusted Goodness Fit Index, RMSEA: Root Mean Square Error of Approximation, $\chi^{2 / d f:} \chi^{2}$ to the degree of freedom index.

Table 4. Path coefficients for, Sexual function, Anxiety, Depression, Coronavirus induced anxiety, General health, Contamination obsession, marital satisfaction, and QOL. 


\begin{tabular}{|c|c|c|c|c|c|}
\hline Dependent & predictors & $\begin{array}{l}\text { Direct } \\
\text { effect }\end{array}$ & $\begin{array}{c}\text { Indirect } \\
\text { effect }\end{array}$ & $\begin{array}{l}\text { Total } \\
\text { effect }\end{array}$ & $\begin{array}{c}\mathrm{T}- \\
\text { value }\end{array}$ \\
\hline \multirow{6}{*}{$\begin{array}{l}\text { Quality of Life } \\
(\mathrm{R} 2=0.35)\end{array}$} & Sexual Function & 0.16 & - & 0.16 & 2.95 \\
\hline & Anxiety & -0.36 & -0.16 & -0.52 & -8.29 \\
\hline & Depression & - & -0.17 & -0.17 & -4.19 \\
\hline & Coronavirus induced anxiety & 0.44 & -0.71 & -0.27 & -4.63 \\
\hline & General health & -0.47 & - & -0.47 & -2.80 \\
\hline & Marital Satisfaction & 0.20 & - & 0.20 & 3.83 \\
\hline \multirow[t]{2}{*}{ General health } & Coronavirus induced anxiety & 0.87 & 0.08 & 0.95 & 50.01 \\
\hline & Depression & 0.19 & - & 0.19 & 10.29 \\
\hline \multirow[t]{2}{*}{$(\mathrm{R} 2=93)$} & Anxiety & - & 0.13 & 0.13 & 15.53 \\
\hline & Depression & -0.48 & - & -0.48 & -8.79 \\
\hline \multirow{2}{*}{$\begin{array}{l}\text { Sexual Function } \\
(\mathrm{R} 2=0.23)\end{array}$} & Anxiety & - & -0.33 & -0.33 & -7.65 \\
\hline & Coronavirus induced anxiety & - & -0.19 & -0.19 & -6.34 \\
\hline $\begin{array}{l}\text { Anxiety } \\
(\mathrm{R} 2=0.33)\end{array}$ & Coronavirus induced anxiety & 0.57 & - & 0.57 & 11.30 \\
\hline \multirow{2}{*}{$\begin{array}{l}\text { Depression } \\
(\mathrm{R} 2=0.48)\end{array}$} & Anxiety & 0.69 & - & 0.69 & 15.53 \\
\hline & Coronavirus induced anxiety & - & 0.40 & 0.40 & 9.14 \\
\hline \multicolumn{6}{|l|}{$\begin{array}{l}\text { Obsessions } \\
(\mathrm{R} 2=0.34)\end{array}$} \\
\hline $\begin{array}{l}\text { Marital } \\
\text { Satisfaction }\end{array}$ & Anxiety & -0.25 & - & -0.25 & -4.12 \\
\hline$(\mathrm{R} 2=0.06)$ & Coronavirus induced anxiety & - & -0.14 & -0.14 & -3.87 \\
\hline
\end{tabular}

\section{Figures}




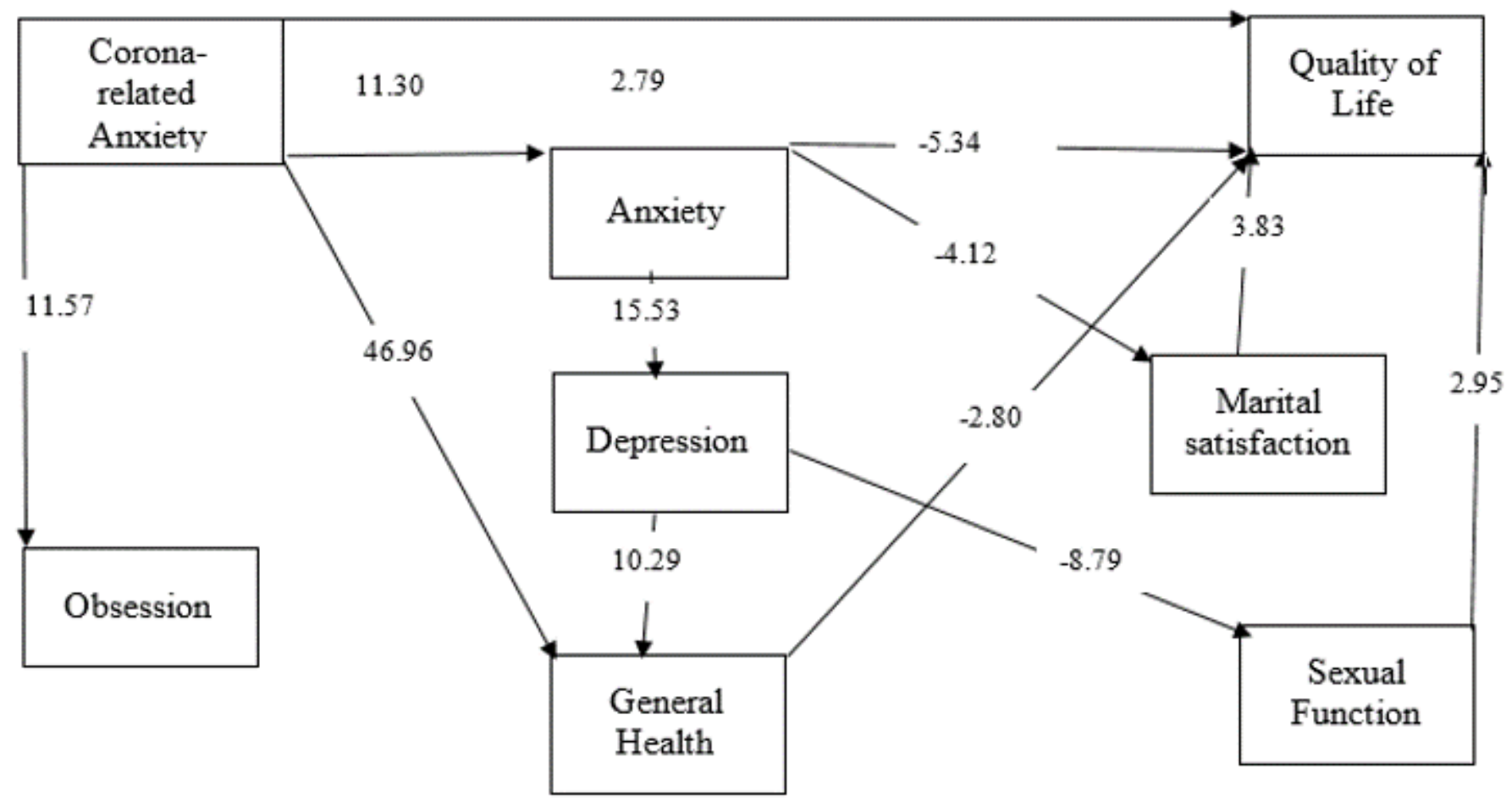

Figure 1

Path diagram (T-value) for the predictors of quality of life

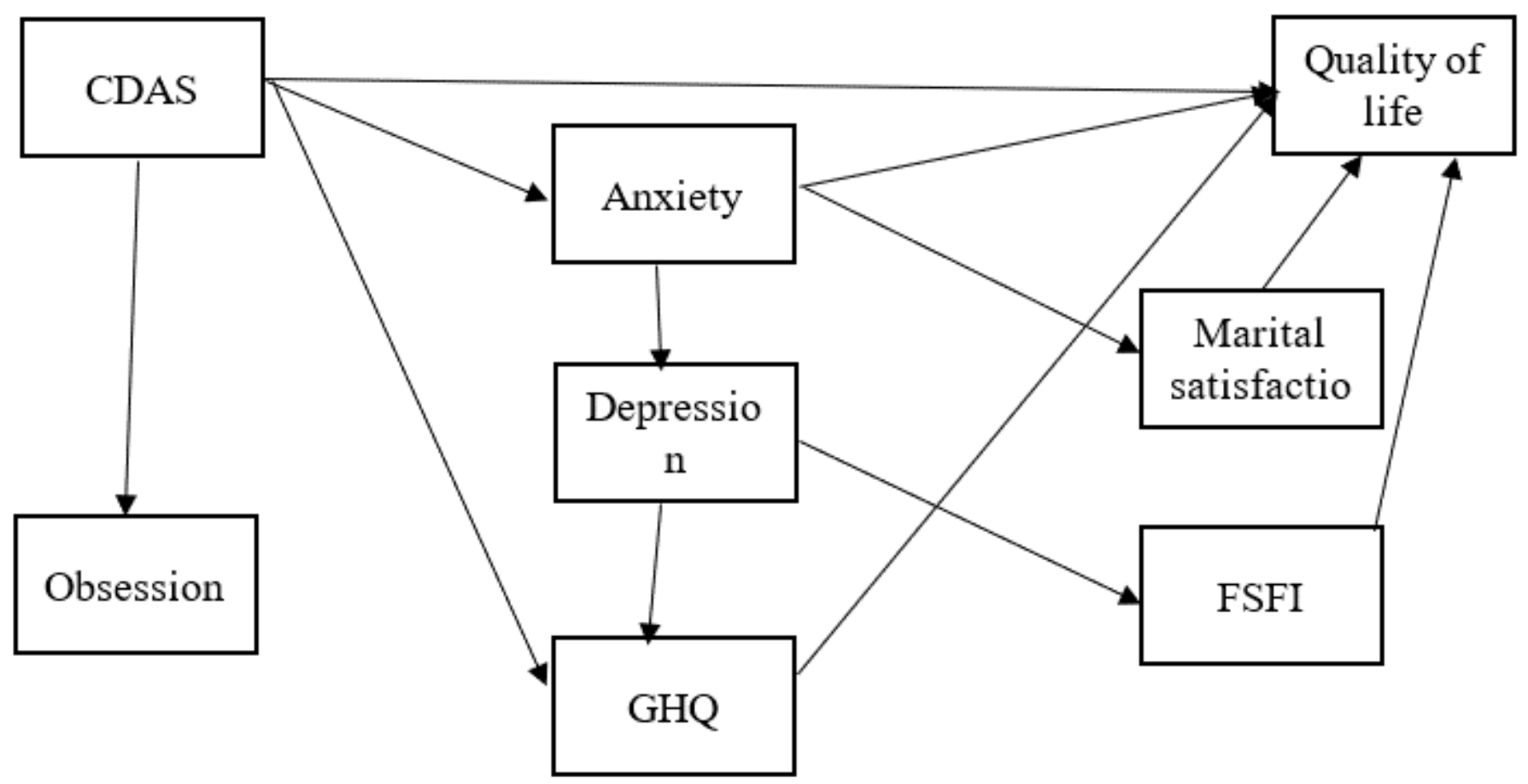


Figure 2

Conceptual Model 